\title{
LA ELIMINACIÓN DE LA INMUNIDAD PARLAMENTARIA, ¿LA DECISIÓN MÁS ACERTADA?
}

\section{THE REMOVAL OF THE PARLIAMENTARY IMMUNITY. IS IT THE BEST DECISION?}

* Estudiante del X ciclo de la Facultad de Derecho de la UNIFÉ. Coordinadora del Área de Investigación del Círculo de Estudios de Derecho Constitucional y Derechos Humanos - CEDEC UNIFÉ

** Estudiante del X ciclo de la Facultad de Derecho de la UNIFÉ. Miembro del Área de Investigación del Círculo de Estudios de Derecho Constitucional y Derechos Humanos - CEDEC UNIFÉ

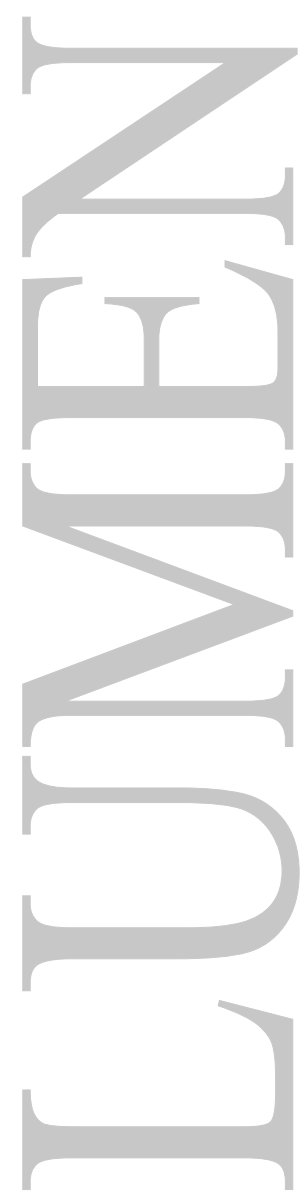




\title{
LA ELIMINACIÓN DE LA INMUNIDAD PARLAMENTARIA, ¿LA DECISIÓN MÁS ACERTADA?
}

\author{
THE REMOVAL OF THE PARLIAMENTARY IMMUNITY. \\ IS IT THE BEST DECISION?
}

López Aburto, Yerina Rocio

Nicolás de la Cruz, Jakelín Verónica

\begin{abstract}
RESUMEN:
Como parte de la Reforma Política impulsada por el gobierno de Martín Vizcarra, se propuso la reforma de la Inmunidad Parlamentaria al ser una prerrogativa institucional muy criticada. $Y$ atendiendo a la presión popular, en julio de 2020 el Congreso de la República aprobó en primera votación la eliminación de la inmunidad de los congresistas, y la de otros funcionarios. Para que la eliminación de la inmunidad parlamentaria se haga efectiva, se requiere de una segunda votación que se llevará a cabo en el 2021. En ese sentido, es propósito del presente artículo analizar si la eliminación de esta garantía constitucional resulta ser la decisión más acertada para nuestra democracia constitucional.
\end{abstract}

\section{PALABRAS CLAVE:}

Derecho Constitucional, Inmunidad Parlamentaria, reforma constitucional, eliminación de la inmunidad parlamentaria.

\section{ABSTRACT:}

As a part of the political reform promoted by the government of Matín Vizcarra, it was proposed the reform of Parliamentary Immunity, because it is an institutional prerogative criticized. Attending to the popular pressure, in july 2020 the Parliament approved in the first vote the removal of parliamentary immunity of the members of the parliament and other officials. To make effective the removal of parliamentary immunity it requires a second vote, that will take place in 2021. In that way, the purpose of this article is to analyze if the removal of this constitutional guarantee is the best decision for our constitutional democracy.

\section{KEY WORDS:}

Constitutional Law, Parliamentary Immunity, constitutional reform, removal of parliamentary immunity.

\section{INTRODUCCIÓN}

Dentro de nuestro ordenamiento jurídico se prevén algunas prerrogativas que sirven como garantía para salvaguardar la independencia y el correcto funcionamiento de nuestras instituciones frente a las injerencias de otras. Una de estas prerrogativas es la inmunidad parlamentaria. Esta es una garantía institucional que tiene como finalidad la protección de la función congresal y del Poder Legislativo, de manera que los congresistas, ante procesos que tengan un trasfondo político, no puedan ser procesados y/o detenidos durante el ejercicio de sus funciones.

Esta prerrogativa, sin embargo, ha sido objeto de constantes críticas por el uso inadecuado por parte del Congreso, por lo que se ha visto la necesidad de plantear una reforma en torno a ella. Para la reforma constitucional de la inmunidad parlamentaria se han propuestos dos alternativas: realizar una reforma propiamente dicha o retirarla de nuestro ordenamiento jurídico. Las opiniones en torno a estas dos propuestas están divididas, por ello resulta necesario el estudio y análisis de los alcances y contenido de esta institución parlamentaria, así como de su aplicación práctica, a fin de determinar si en el Perú del siglo XXI todavía se encuentra vigente. 
En el presente artículo, realizaremos un análisis de las reformas planteadas en torno a la inmunidad parlamentaria, como la propuesta aprobada en una primera votación que elimina la inmunidad parlamentaria y reduce las prerrogativas de otros funcionarios. Para ello, realizaremos una previa indagación en sus orígenes, y su tratamiento jurídico interno; mencionaremos seguidamente su aplicación práctica en nuestro país, a través del análisis de casos en los que esta figura fue mal utilizada y que generaron un rechazo popular, lo que supuso se plantee propuestas de reforma en torno a ella, las cuales serán presentadas, recurriendo, además, al derecho comparado; $y$, finalmente presentaremos nuestra postura en torno a esta reforma, proponiendo además criterios que se deben tener en cuenta en aras de lograr una reforma integral.

\section{Orígenes de la Inmunidad Parlamentaria}

En la historia reciente, los orígenes de la inmunidad parlamentaria se remontan al Parlamento de la Inglaterra medieval, donde se desarrollaron dos tradiciones practicadas por los miembros del parlamento para hacer frente al poder autoritario del Rey. Así, surgieron el "freedom of speech" y el "freedom from arrest".

El "freedom of speech" era una prerrogativa de los miembros del parlamento para debatir y deliberar los asuntos de su competencia con total libertad, sin tener que preocuparse por la intervención del Rey; por su lado, el "freedom from arrest" suponía la imposibilidad del monarca de ordenar la privación de la libertad de los miembros del parlamento por asuntos de carácter civil, sobre todo cuando estos se encontraban trasladándose desde o hacia el Parlamento. Esta segunda prerrogativa, "freedom from arrest", dejó de tener vigencia cuando en Inglaterra se abolió la prisión por deudas. Caso contrario, el "freedom of speech" aún se sigue practicando en la mayoría de países, aunque con ciertas variaciones. (Comisión de Venecia, 2014, p. 5).

La Revolución francesa de 1789 trajo consigo cambios importantes para el sistema parlamentario. La Asamblea Nacional francesa declaró que "the person of each deputy shall be inviolable". De esa manera, la Asamblea confirió a los parlamentarios una prerrogativa amplia para que no sean objeto de cualquier tipo de acciones judiciales que se pudieran promover en su contra. Empero, con el tiempo, los casos de flagrante delicto se establecieron como una excepción, y se le dio a la Asamblea la competencia para levantar la inmunidad parlamentaria en tales supuestos. (Comisión de Venecia, 2014, p. 5).

En el parlamentarismo inglés se dieron los primeros bosquejos para la institución de la inmunidad parlamentaria, pero fue en el parlamentarismo francés que se establecieron las bases del modelo que predomina hoy en día.

Siendo así, en los sistemas parlamentarios actuales podemos identificar dos categorías de la Inmunidad Parlamentaria: la inviolabilidad y la inmunidad en sentido estricto. La primera categoría contempla una amplia protección de los parlamentarios respecto de los votos y opiniones que emitan en el ejercicio de sus funciones; mientras que la segunda categoría consiste en que los miembros del parlamento no pueden ser detenidos ni procesados por la supuesta comisión de delitos sin el consentimiento previo del Parlamento. (Comisión de Venecia, 2014, p. 4).

Hay un consenso sobre el tratamiento jurídico y práctico de la inviolabilidad; se reconoce su importancia como garantizador de la función parlamentaria, y en la mayoría de países esta es absoluta y no puede ser levantada. Por el contrario, se ha generado un debate respecto de la inmunidad en sentido estricto, por la forma en la que ha venido siendo aplicada en muchos países. Se considera que ha pasado de ser una prerrogativa propia de la función parlamentaria a ser un privilegio personal de los miembros del parlamento, por lo que muchas voces consideran debe suprimirse. 


\section{Tratamiento jurídico interno de la Inmunidad Parlamentaria}

Primero que todo, es importante señalar que según expresó el Tribunal Constitucional, mediante sentencia Exp. $\mathrm{N}^{\circ}$ 00026-2006-PI/TC, la inmunidad parlamentaria constituye una garantía institucional del Parlamento, pues está destinada a la protección de la función congresal y del propio Poder Legislativo. En ese sentido, no puede ser concebida como un derecho subjetivo de los congresistas. (fundamento 15)

La Constitución Política del Perú de 1993, en su artículo 93 ${ }^{\circ}$ contempla a la Inmunidad Parlamentaria en sus dos vertientes. Sobre la prerrogativa de la inviolabilidad de opinión y voto expresa que los congresistas "no son responsables ante autoridad ni órgano jurisdiccional alguno por las opiniones y votos que emiten en el ejercicio de sus funciones"; y sobre la inmunidad en sentido estricto, o "inmunidad parlamentaria" como coloquialmente se la conoce, sostiene que los congresistas "no pueden ser procesados ni presos sin previa autorización del Congreso o de la Comisión Permanente, desde que son elegidos hasta un mes después de haber cesado en sus funciones, excepto por delito flagrante (...)".

Dadas las intenciones del presente artículo de investigación, corresponde hacer un análisis sobre la inmunidad en sentido estricto para determinar sus alcances y los supuestos que conllevan a su levantamiento.

El artículo 16 del Reglamento del Congreso expresa que la "inmunidad parlamentaria" solo opera respecto de las acciones judiciales de carácter penal que se promuevan en contra de los congresistas, por tanto, las causas civiles y administrativas quedan excluidas del alcance de esta prerrogativa. Asimismo, dada la naturaleza misma de esta institución, solo comprende a los delitos comunes, siendo que para los delitos funcionales está la figura de la acusación constitucional prevista en el artículo $99^{\circ}$ de la Constitución (STC Exp. Nº0013-2009-Al/TC, fundamento 36).

Esta prerrogativa además es de carácter temporal, tiene vigencia desde la proclamación del congresista como tal por el Jurado Nacional de Elecciones (STC Exp. N 26-2006-AI/TC, fundamento 29) hasta un mes después de haber cesado en sus funciones.

Del texto de la Constitución se extrae que en la legislación peruana hay dos tipos de inmunidad en sentido estricto o "inmunidad parlamentaria": la inmunidad de arresto y la inmunidad de proceso.

La inmunidad de arresto impide que los congresistas sean detenidos o encarcelados sin previa autorización del congreso, en razón de los procesos penales iniciados antes de ser proclamados congresistas o después de ello, pero siempre que el pedido sea dentro del periodo establecido por ley. Sobre esta prerrogativa, mediante informe titulado "Inmunidad Parlamentaria, breve análisis de esta prerrogativa", Proética ha identificado algunos vacíos legales respecto del procedimiento de levantamiento de la inmunidad de arresto que no han sido regulados ni por el Reglamento del Congreso ni por el Tribunal Constitucional a través de sus sentencias; situación que "han generado incertidumbre y decisiones distintas respecto de cómo se deben tramitar estos pedidos dentro del Congreso" (2019, p. 12). A partir del caso del congresista Edwin Donayre, la Comisión de Constitución y Reglamento del Congreso mediante Informe de Opinión Consultiva 02-2018-2019, refirió que el levantamiento de la inmunidad de arresto sigue el mismo procedimiento que el de la inmunidad de proceso, y que para aprobar el pedido es necesario una sentencia firme.

Por otro lado, la inmunidad de proceso impide que se inicie un proceso penal contra un congresista sin previa autorización del congreso, y dentro del plazo establecido por ley. No importa el momento en el que ocurrieron los hechos, sino que el pedido del levantamiento de la inmunidad se haga dentro del ejercicio del cargo como congresista. Además, esta prerrogativa no contempla a los procesos iniciados antes de la proclamación del congresista, por lo que pueden seguir su curso normal; sin 
embargo, en tal supuesto los congresistas aún mantienen su inmunidad de arresto. (STC Exp. $\mathrm{N}^{\circ}$ 00026-2006-PI/TC, fundamento 29)

Los casos de delito flagrante suponen una excepción a estas garantías parlamentarias. Según el artículo $93^{\circ}$ de la Constitución, cuando un congresista es sorprendido cometiendo algún ilícito penal, este podrá ser detenido y deberá ser puesto a disposición del Congreso, o de la Comisión Permanente cuando el primero esté en receso, dentro de las veinticuatro horas, a fin de que se autorice o no el levantamiento de su inmunidad para ser enjuiciado o privado de su libertad.

\section{Sobre el levantamiento de la Inmunidad Parlamentaria}

En el Perú, el Congreso de la República es el órgano que tiene la competencia para levantar la inmunidad de los congresistas. Esta es una práctica que tienen la mayoría de los países al ser la inmunidad parlamentaria una garantía institucional que históricamente ha buscado proteger al Parlamento respecto de la intervención de los otros poderes sobre sus funciones. Solo Chile y Andorra le han cedido esta competencia a la Corte de Apelaciones, y La República de Chipre, a la Corte Suprema. (Comisión de Venecia, 2014, pp. 21- 22)

El procedimiento para el levantamiento de la inmunidad parlamentaria se encuentra regulado en el artículo 16 del Reglamento del Congreso, así como en los artículos $452^{\circ}$ y $453^{\circ}$ del Código Procesal Penal. Este se inicia cuando el juez a cargo del proceso contra un congresista solicita, de oficio o a pedido del fiscal, el levantamiento de la inmunidad parlamentaria ante la Corte Suprema de Justicia (CSJ). La CSJ evalúa el pedido y de estar conforme lo remite al presidente del Congreso de la República, quien, a su vez, dentro de las 24 horas siguientes, deriva el pedido a la Comisión de Levantamiento de Inmunidad Parlamentaria. Sin pronunciarse sobre el fondo, la Comisión califica la solicitud del Poder Judicial y decide si la admite o no; de admitirse, y previo descargo del congresista imputado, la Comisión elabora un dictamen recomendando al Pleno del Congreso declare procedente o improcedente el levantamiento de la inmunidad. El Pleno del Congreso debate el dictamen enviado, escucha al acusado, y realiza la votación correspondiente; siendo que, si se obtiene como votos a favor la mitad más uno del número legal de congresistas, se aprueba el levantamiento de la inmunidad o, en su defecto, se archiva. Finalmente, la Comisión de Levantamiento de Inmunidad Parlamentaria comunica a la Corte Suprema de Justicia la decisión del Pleno del Congreso.

El levantamiento de la inmunidad en sentido estricto supone una decisión política. Cuando se presenta un pedido de levantamiento de la inmunidad parlamentaria el Congreso solo debe evaluar la existencia de motivaciones de índole política, racial, religiosa o de otra naturaleza discriminatoria (artículo 16.2 del Reglamento del Congreso) que pretendan perturbar el correcto funcionamiento de la función congresal, siendo que cuando no se identifiquen tales motivos en las acusaciones, el Congreso debe levantar la inmunidad del congresista imputado. (STC Exp. 00006-2003-AI/TC, fundamento 5). Se entiende entonces que por regla general se debe aprobar el levantamiento de la inmunidad, siendo la excepción los casos en los que se identifiquen móviles extrajurídicos en las acusaciones.

El problema radica precisamente en la evaluación que hace el Congreso respecto de los pedidos de levantamiento de la inmunidad. En la práctica, se han dado muchos casos en los que el Congreso asume el papel de juzgador y evalúa si existen suficientes medios probatorios que acrediten la comisión del delito del congresista acusado, supeditando su decisión a tales consideraciones.

\section{Sobre la aplicación de la Inmunidad Parlamentaria en el Perú}

Los casos en los que se han solicitado el levantamiento de la inmunidad parlamentaria en nuestro país han sido muy controversiales, ya que en los diversos periodos legislativos el Poder Judicial ha 
presentado diversos pedidos para que se levante esta prerrogativa, pero solo un porcentaje muy reducido de estos han sido aprobados.

En mayo de 2019, el entonces presidente del Consejo de Ministros, Salvador del Solar, en una entrevista que brindó a RPP señaló que entre los periodos legislativos de 1995 al 2020, se habían presentado, aproximadamente, 110 pedidos de levantamiento de inmunidad parlamentaria, pero solo el $10 \%$ de estas habían sido aceptadas. Declaraciones que por supuesto generaron en la población un rechazo aún mayor sobre esta prerrogativa constitucional.

Pero, ¿qué tan cierta es esta declaración? Para poder tener una idea podemos tomar como referencia el informe "Inmunidad Parlamentaria, breve análisis de esta prerrogativa" elaborado por Proética. De la información solicitada al Congreso, precisó que en el período legislativo de 2006 al 2011, de las 16 solicitudes presentadas, tres no fueron revisadas ni discutidas, y solo 4 fueron aprobadas por la Comisión de levantamiento de Inmunidad parlamentaria y remitidas al Pleno del Congreso, las cuales, sin embargo, al no ser incluidas en la agenda terminaron por ser archivadas. En el periodo 2011-2016, de los 14 pedidos presentados, 7 fueron aprobados por la Comisión y remitidas al Pleno del Congreso, de los cuales solo fueron aprobados 3. Por último, en el periodo 2016 al 2019, se han presentado 10 solicitudes, 4 de estas fueron desaprobadas y 4 aprobadas en la Comisión encargada, y remitidas al Pleno del Congreso.

Días después de las declaraciones de Salvador del Solar, la periodista Carla Díaz realizó una publicación para Ojopúblico en el que detalló que desde 1995 al 2019 se han presentado 88 pedidos de levantamiento de inmunidad parlamentaria. En el periodo de 1995 al 2000, se presentaron 17 pedidos, siendo solo aprobado el requerimiento contra Javier Noriega Febres del partido político Frepap. Durante el periodo de 2001 al 2006, de las 41 solicitudes de levantamiento de inmunidad parlamentaria, solo fueron aprobadas 2. En el periodo de 2011 al 2016, de los 12 pedidos presentados solo fueron aprobadas 3. Por último, en el periodo de 2016 al 2019, se presentaron 8 pedidos.

Los datos antes señalados sirven para confirmar que del total de solicitudes presentadas por el Poder Judicial para levantar la inmunidad de los congresistas, solo un reducido número de estas han sido aprobadas.

Ahora bien, en el grupo de las solicitudes presentadas por el Poder Judicial para que aprueben el levantamiento de la Inmunidad parlamentaria, podemos destacar algunos casos en los que se pueden denotar el mal manejo de esta esta figura.

\section{- Caso Betty Ananculi Gómez}

En un reportaje emitido por el programa dominical Cuarto Poder, en abril de 2018, se reveló que la congresista de Fuerza Popular por la región Ica consignó información falsa en la hoja de vida que presentó ante el Jurado Nacional de Elecciones (JNE). Según el reportaje, ella consignó que entre los años 2011 y 2013, cursó la carrera de Administración de Negocios Internacionales en el Instituto Alas Peruanas de Ica, sin embargo, los certificados de estudios presentados habían sido presuntamente adulterados.

En setiembre del mismo año, el Poder Judicial presentó el pedido de levantamiento de inmunidad parlamentaria ante la Comisión encargada, para investigarla por el presunto delito de falsificación de documentos y uso de documentos públicos falsos en agravio del Estado. Sin embargo, y a pesar de que la secretaría técnica de la Comisión de levantamiento de Inmunidad Parlamentaria había recomendado declarar procedente el pedido, la Comisión, integrada en su mayoría por congresistas de Fuerza Popular, archivó el pedido. 
A principios de junio de 2019, el Poder Judicial volvió a solicitar se le levante la inmunidad parlamentaria por el presunto delito de falsa declaración en procedimiento administrativo y falsedad genérica, presentado como nuevos hechos la declaración de los docentes, consignada en los documentos de estudio que había presentado la congresista, quienes aseguraron no haber tenido a Ananculi como alumna en el referido instituto. Esta vez la secretaría técnica recomendó se declare improcedente el pedido, lo que fue aprobado por mayoría el 19 de junio de ese mismo año, declarando así improcedente el pedido del Poder Judicial.

\section{- Caso Edwin Donayre Gotzch}

En el 2016, Edwin Donayre fue elegido como congresista por el partido político Alianza para el Progreso (APP), sin embargo, no llegó a concluir su periodo, ya que en el 2019 el Pleno del Congreso aprobó se le levante la inmunidad parlamentaria por pesar sobre él una condena de 5 años de pena privativa de libertad.

En agosto de 2018, la Segunda Sala Penal Liquidadora de la Corte Superior de Lima lo sentenció a cinco años y seis meses, por encontrarlo responsable por el delito de peculado en agravio del Estado. Según las investigaciones, cuando el ahora excongresista ejercía el cargo de jefe de la Región Militar del Sur, se habría apropiado de grandes cantidades del combustible, de ahí que el caso fue conocido como "Gasolinazo".

En setiembre de ese año, el Poder Judicial solicitó se le levante la inmunidad parlamentaria para que se ejecute la condena de prisión, pero, un mes después la Comisión de Levantamiento de Inmunidad devolvió la solicitud, señalando que no se había precisado qué tipo de inmunidad se pedía levantar (inmunidad de proceso o inmunidad de arresto), y que al tratarse de una sentencia de primera instancia este no era suficiente para aprobar el levantamiento de la prerrogativa constitucional.

En noviembre, el Poder Judicial reiteró la solicitud señalando que, una sentencia se ejecuta conforme a sus propios términos. La Comisión solicitó una opinión consultiva a la Comisión de Constitución a fin de que se precise si se requería o no una sentencia firme para que se levante la inmunidad de arresto, ya que el congresista había presentado un recurso de nulidad. Muchos congresistas criticaron esta decisión por considerarla innecesaria, ya que se acordó que se esperaría dicho pronunciamiento para resolver el caso. La Comisión de Constitución, recién el febrero de 2019, a través de la Opinión Consultiva 02-2018-2019 se pronunció señalando que en este tipo de casos "lo coherente normativa y constitucionalmente es que la condena sea firme" (p. 23), por lo que recomendaron se solicite al Poder Judicial precise la situación del congresista.

Es recién el 2 de abril de 2019 que la Comisión decidió por unanimidad admitir a trámite el pedido, y el 5 de abril, el congresista con su abogado se presentó ante la Comisión para ejercer su derecho a la defensa. Semanas después, el 29 de abril, la Sala Suprema Penal Permanente del Poder Judicial confirmó en última instancia la sentencia de primera instancia y ordenó que cumpla 5 años de prisión efectiva.

Teniendo en cuenta esta sentencia, y la presión popular, el 2 de mayo de 2019, con 102 votos a favor, el Pleno del Congreso de la República aprobó levantarle la inmunidad parlamentaria, y el Poder Judicial ordenó su captura inmediata, sin embargo, cuando la Policía inició su búsqueda no lograron ubicarlo en su hogar.

Por varios meses el paradero del congresista fue desconocido, llegando inclusive a ser incluido, por el Ministerio del Interior, en la lista de personas buscadas, ofreciéndose una recompensa por su ubicación de más de 100,000 mil nuevos soles. Finalmente, el 30 de octubre fue capturado por la policía en Puente Piedra. 


\section{- Caso Carlos Raffo Arce}

En el 2004, Carlos Raffo fue acusado de haber recibido dinero de Vladimiro Montesinos, como parte de la campaña de reelección del expresidente Alberto Fujimori, por ello se le imputó el delito de peculado en agravio del Estado, por lo que se solicitó se le imponga 5 años de pena privativa de libertad.

En diciembre de 2008, la Cuarta Sala Penal Especial de la Corte Superior de Lima emitió un auto en el que señaló que existían suficientes pruebas para iniciar juicio contra el ya entonces congresista por el partido Alianza por el Futuro. Él dedujo una excepción de naturaleza de acción por tener la condición de congresista, excepción que fue declarada infundada, y se solicitó que se le levante la inmunidad parlamentaria.

En marzo de 2009, fue declarado reo contumaz, por las reiteradas inasistencias a las audiencias, y se dispuso su captura para que sea conducido a la sede de la Sala Penal Especial y participe de la audiencia. Esta resolución, sin embargo, fue declarada nula, y se ordenó que se formalice la solicitud de levantamiento de inmunidad parlamentaria.

El Poder Judicial presentó la solicitud en marzo de 2010, la misma que fue declarada improcedente el 10 de junio del mismo año. La Comisión de Levantamiento de inmunidad parlamentaria señaló que, de la evaluación del caso no se podía advertir la existencia de una motivación estrictamente legal, sino que por el contrario el caso tenía un trasfondo político, ya que el proceso del autor del delito ya había sobreseído, por lo que no se podía seguir investigando a Carlos Raffo, ya que él fue acusado como autor primario; además que no existía una conducta rebelde por parte de Carlos Raffo. Señaló, además, que el órgano judicial sabiendo que él ostentaba una prerrogativa constitucional ordenó su detención, contraviniendo el procedimiento establecido en la Constitución para estos casos. (Tacuche, 2017, pp 29-31)

La decisión de archivar o declarar improcedente los pedidos de levantamiento de inmunidad parlamentaria en los casos antes mencionados no fueron bien recibidas por la ciudadanía, ya que consideraron que esta prerrogativa era mal utilizada por los congresistas para de alguna manera blindarse y no ser investigados o privados de su libertad. De igual manera, la demora de la Comisión para resolver los pedidos generó una desconfianza aún mayor en los ciudadanos, quienes llegan a confundir esta garantía institucional como una forma de impunidad, desvirtuándose así el propósito de esta prerrogativa.

Incluso, en una encuesta realizada en noviembre de 2019, por El Comercio e Ipsos, el $78 \%$ de los peruanos consideró que los congresistas no deberían gozar de inmunidad parlamentaria. De igual manera, el $80 \%$ de la población de Lima estaba de acuerdo con que se elimine esta prerrogativa; y el $12 \%$ consideraba que debía reformarse la inmunidad parlamentaria, en el sentido de que sea otro órgano el que decida si procede o no levantarla.

\section{Propuestas de reforma de la Inmunidad Parlamentaria}

En el 2018, se iniciaron una serie de reformas en nuestro país. La primera de ellas fue el referéndum en el que se les consultó a los ciudadanos sobre la reforma al Consejo Nacional de la Magistratura, la no reelección inmediata de congresistas, el financiamiento público a los partidos políticos y el retorno a la bicameralidad. Después, en diciembre, el Ejecutivo creó la Comisión de Alto Nivel para la Reforma Política, con la finalidad de presentar una serie de propuestas para fortalecer y mejorar las instituciones del sistema democrático y del Estado Constitucional de Derecho. Esta Comisión presentó su informe final en marzo de 2019, en el que incluyó 12 proyectos de reformas, siendo uno de ellos la reforma de la inmunidad parlamentaria. (Proética, 2019, p. 26) 
Las propuestas de reforma de esta prerrogativa son dos muy marcadas. La primera consiste en mantener la inmunidad parlamentaria pero que sea otro órgano distinto al congreso el que decida si procede o no levantar esta prerrogativa, y la segunda propuesta plantea su eliminación.

\section{- Propuesta de revisión por parte de un órgano distinto al Congreso}

En un primer momento esta propuesta fue presentada por el Poder Ejecutivo, dentro de los 12 proyectos de reformas elaborados por la Comisión de Alto Nivel para la Reforma Política. Así, con el proyecto Ley № 4192-2018-PE, se propuso que ya no sea el Congreso el que decida el levantamiento de la inmunidad parlamentaria, sino la Corte Suprema de Justicia. Esta propuesta, sin embargo, en mayo de 2019, fue archivada por la Comisión de Constitución.

El Ejecutivo reiteró esta propuesta el 4 de junio de 2019, a través del Proyecto de Ley $N^{\circ} 4416-$ 2018-PE. El Proyecto planteaba mantener la protección que brinda la Inmunidad Parlamentaria en el ámbito penal, pero proponía que sea la Corte Suprema de Justicia, y ya no el Congreso, el órgano encargado de evaluar las denuncias contra los congresistas por delitos comunes, y en caso se verificara la existencia de un sustento jurídico en las denuncias, sea esta misma la que se encargue del procesamiento de los congresistas. Otros aspectos de este proyecto estaban referidos a que se establezca un fuero especial en la Corte Suprema de Justicia para los congresistas; y que el plazo para pronunciarse sobre los pedidos sea de 30 días improrrogables.

Existieron, además, propuestas presentadas por Acción Popular en las que plantean que sea la Junta Nacional de Justicia y el Tribunal Constitucional los órganos encargados de levantar esta prerrogativa constitucional, mediante Proyecto Ley No 4882/2020-CR y Proyecto Ley No 4939/2020$\mathrm{CR}$, respectivamente.

Podría resultar atractivo que sea un poder distinto al Poder Legislativo el encargado de levantar la inmunidad parlamentaria de los congresistas por todos los cuestionamientos que se le ha hecho al Congreso en el ejercicio de dicha tarea, pero, ¿qué tan factible sería esta opción? Si tomamos en cuenta los proyectos ley que proponen que sea la Junta Nacional de Justicia o el Tribunal Constitucional los órganos encargados de esta tarea es preciso mencionar que estos órganos constitucionalmente autónomos ya cuentan con funciones determinadas por la propia Constitución y sus leyes orgánicas. Entre las funciones propias de la JNJ está nombrar, previo concurso público de méritos y evaluación personal, a los jueces y fiscales, y por su parte, el Tribunal Constitucional vela por la defensa de la supremacía constitucional, por ello es considerado como el órgano de interpretación y control constitucional. Por tanto, sumar una función más a dichos órganos no sería lo más adecuado, ya que, como es en el caso del Tribunal Constitucional esto conlleva a aumentar la carga procesal.

Por ello, tienen mayor peso las razones que nos inclinan a sostener que esta competencia solo puede recaer sobre el Poder Legislativo. Primero que todo, como ya se ha señalado, no se debe olvidar que la inmunidad parlamentaria es una garantía institucional cuya finalidad es proteger la función parlamentaria y a la institución misma de las injerencias que los otros poderes puedan tener sobre ella. Delegar la competencia sobre el levantamiento de la inmunidad parlamentaria a un ente distinto, sería dejar al Parlamento a merced de sus verdugos.

Un ejemplo de lo dicho es Chile. Como lo mencionamos párrafos supra, de conformidad con el artículo $61^{\circ}$ de la Constitución Política de Chile, la Corte de Apelaciones es la encargada de autorizar el procesamiento o la privación de la libertad de los miembros de sus cámaras. De la experiencia del parlamentarismo chileno, se tiene que la Corte de Apelaciones no realiza un análisis sobre la existencia de motivaciones extralegales de las acusaciones presentadas contra los miembros del parlamento, sino que evalúa la existencia de indicios que determinen la culpabilidad del imputado. 
(Canales \& Loiseau, 1999, pp. 21-22) Dicha práctica resulta cuestionable por ser contraria a la finalidad de la inmunidad parlamentaria.

\section{- Propuesta de eliminación de la inmunidad parlamentaria}

Otra de las propuestas de reforma sobre esta prerrogativa es la de su eliminación. La primera propuesta fue presentada en marzo de 2018, a través del Proyecto de Ley 2613/2017-CR por la congresista Patricia Donayre Pasquel, con la finalidad de eliminar el tercer párrafo correspondiente a la imposibilidad de ser investigados en procesos judiciales. Este proyecto, que podría considerarse como radical, implicaba, según Proética (2019), desaparecer la garantía procesal de las que gozaban los parlamentarios como miembros del Poder Legislativo, y ser investigados, procesados, sancionados y/o detenidos como cualquier ciudadano, bajo las reglas establecidas en el Código Procesal Penal. (pp. 29-30)

Este año, dado el exponencial rechazo popular a esta institución, durante la campaña electoral de las elecciones congresales extraordinarias 2020, los diversos partidos o agrupaciones políticas presentaron como parte de su plan de trabajo la reforma de la inmunidad parlamentaria, planteando para tal propósito su eliminación. Se presentaron alrededor de 14 Proyectos Ley con este mismo fin. Así, podemos señalar los proyectos ley presentados por Somos Perú, Frente Popular Agrícola del Perú (Frepap), quienes incluso plantearon la eliminación del antejuicio político, Podemos Perú, Alianza para el Progreso (APP), entre otros.

Entre los países de la Región se tiene que Colombia, Honduras, Panamá y Bolivia han eliminado la inmunidad parlamentaria de sus textos constitucionales en los años 1991, 2003, 2004 y 2009 , respectivamente (Proética, 2019, p. 19). Dado el tiempo que ha transcurrido en cada uno de dichos países, se podría indagar sobre la experiencia de cada uno, a manera de proyectar las consecuencias que la eliminación de la inmunidad traería al Perú, sin olvidar, claro está, que cada nación tiene una realidad distinta.

\section{Análisis sobre la reforma de la Inmunidad Parlamentaria aprobada en primera votación}

El primero de julio del presente año, la Comisión de Constitución presentó un dictamen en el que recomendó la aprobación de los proyectos de ley presentados por los distintos partidos políticos, y propuso un texto sustitutorio. Dicho texto señalaba que los procesos penales iniciados contra los congresistas por delitos comunes cometidos durante el ejercicio de su función eran competencia exclusiva de la Corte Suprema. Este dictamen fue sometido a votación dos días después, no alcanzando los 87 votos que se requerían para su aprobación. Frente a esta decisión del Congreso, el presidente Martín Vizcarra anunció, para el 2021, un referéndum para eliminar la inmunidad parlamentaria.

Después de este anuncio, el presidente del congreso, Manuel Merino, convocó a una sesión extraordinaria. En esta nueva sesión se debatió un nuevo texto sustitutorio elaborado por la Comisión de Constitución el 4 de julio; sin embargo, fue presentado un texto distinto al original, ya que se incluía la reducción de prerrogativas constitucionales al presidente, los ministros de Estado, los magistrados del Tribunal Constitucional, y los jueces y fiscales supremos. Así, el texto planteaba la modificación de los artículos 93, 99, 117, 161 y 201 de la Constitución. Finalmente fue aprobado con 111 votos a favor y 14 en contra.

Esta noticia fue considerada por algunos como una decisión histórica; sin embargo, también fue muy criticada, ya que consideraban que el texto sustitutorio aprobado no se había discutido en la Comisión de Constitución ni mucho menos en el Pleno del Congreso, tampoco se había tenido en cuenta la opinión de expertos en el tema, por ello algunos constitucionalistas se atrevieron a señalar que podía ser declarada como inconstitucional por la forma, y que al haber reducido prerrogativas de otros entes del Estado vulneraría la autonomía de estos. 
El primero en cuestionar la decisión del Congreso fue el presidente Martín Vizcarra, quien en sus declaraciones a los medios de comunicación señaló que para él se vulneró el debido proceso, y el texto finalmente aprobado adolece de vicios de inconstitucionalidad. Por ello, considera que podría tratarse de un artificio para que al ser declarado inconstitucional siga manteniéndose la inmunidad parlamentaria, distorsionando así la finalidad de la reforma constitucional planteada. Por su parte, la presidenta del Tribunal Constitucional, Marianella Ledesma, también en declaraciones a los medios de comunicación, cuestionó que el texto sustitutorio haya sido aprobado sin antes haberse analizado y discutido a profundidad, ya que sostiene que dicha reforma vulnera la autonomía de los magistrados y los jueces, así como el modelo democrático de nuestro país, por lo que aseguró que en caso sea aprobado en la segunda votación está la posibilidad de recurrir a órganos internacionales, como la Corte Interamericana de Derechos Humanos, con la finalidad de resguardar la autonomía de los magistrados.

Algunos expertos en materia constitucional también se han pronunciado alegando su inconstitucionalidad. Así, en declaraciones para RPP, Urviola Hani, expresidente del Tribunal Constitucional, advirtió que, al no haberse respetado un procedimiento adecuado, la reforma aprobada deviene en inconstitucional por la forma, por lo que de ser aprobada en una segunda votación podría demandar su inconstitucionalidad ante el Tribunal Constitucional. Señala, además, que la motivación por la que se decidió aprobar esta reforma constitucional responde a una meramente política y no jurídica. Por su parte, el abogado constitucionalista, Omar Cairo, en declaraciones también para RPP, señala que la reforma aprobada es pasible de que sea declarada parcialmente inconstitucional, ya que para él solo es válida la modificación del artículo 93 de la Constitución, y no la de los artículos 99, 117, 161 y 201, modificaciones que no formaron parte del texto que se sometió a votación.

Ahora bien, la reforma constitucional de la inmunidad parlamentaria tal como fue aprobada fue tergiversada, ya que, si hacemos un análisis del texto sustitutorio aprobado, este incluyó modificaciones de otros artículos de la Constitución que no fueron incluidos en los proyectos ley presentados por el Ejecutivo ni tampoco en los presentados por los diversos partidos o agrupaciones políticas, así como tampoco fueron discutidos a cabalidad. Las reformas constitucionales requieren de una deliberación profunda para analizar todas las aristas y consecuencias que se podrían suscitar en torno a esa reforma. Si bien la eliminación de esta prerrogativa formó parte de la campaña electoral de la gran mayoría de los partidos, finalmente parecería que fue aprobada por la presión popular sin tener en cuenta que, si vuelve a ser aprobada en la segunda votación pendiente, podría ser pasible de una demanda de inconstitucionalidad. Sin duda, se perdió la oportunidad de lograr una reforma que tuviese como finalidad una mejor regulación de esta prerrogativa.

\section{Opinión}

A lo largo del presente artículo se han expuesto y ejemplificado razones que justificarían la eliminación de la "inmunidad parlamentaria" como prerrogativa institucional. La tendencia a nivel mundial también se orienta a la supresión de esta institución jurídica. Empero, debemos tener presente que esta es una decisión que compete a cada nación, y antes de tomar una decisión radical motivada por pasiones del momento, resulta necesario conocer también los argumentos que justificarían el mantener la inmunidad en sentido estricto.

Se dice que los argumentos históricos que dieron origen a la "inmunidad parlamentaria", como la división de poderes en sentido estricto y la lucha de legitimidad entre los poderes del Estado, ya no están vigentes en tiempos donde predominan los Estados democráticos y de derecho, pues si bien se reconoce la independencia de cada uno de ellos, existen pesos y contrapesos que hacen difícil la presión de los otros poderes respecto del Poder Legislativo. Al respecto, nuestra historia política nos demuestra que lo alegado no es del todo cierto. A diferencia del sistema parlamentarista 
del Reino Unido, donde el Prime Minister (jefe de gobierno) es el representante del partido político con mayoría parlamentaria en the House of Commons, en el sistema presidencialista peruano no siempre hay coincidencia de partidos entre el presidente de la República y la bancada mayoritaria del Congreso, siendo que estos últimos constituyen la oposición del gobierno de turno. En ese sentido, vemos que aún en tiempos de democracia, existe esta confrontación entre poderes. Por ello, la inmunidad parlamentaria viene a ser una prerrogativa necesaria para garantizar el correcto funcionamiento del Congreso de la República.

En su mayoría, las críticas se centran en la forma en cómo nuestros representantes legislativos han venido aplicando esta prerrogativa institucional. No se puede negar que bajo el argumento de la defensa de la autonomía congresal muchos congresistas han pretendido utilizar esta prerrogativa como un privilegio personal. Pero cierto es también que el actuar de las personas no determina la inutilidad de una institución jurídica. Por ello consideramos que la "inmunidad parlamentaria" es merecedora de ser reformada, mas no de ser eliminada. Con una modificación integral de esta inmunidad se puede asegurar su adecuada aplicación por parte de los congresistas, y seguiría cumpliendo con su finalidad.

Sumado a ello, cabe mencionar que en los últimos años se han emitido ciertas normas que suponen una restricción al mal accionar de los congresistas. Se tiene, por ejemplo, la Ley № 30906 que prohíbe la reelección inmediata de los congresistas, por lo que terminado su periodo de cinco años, podrán ser enjuiciados o privados de su libertad al igual que cualquier ciudadano; así como la Ley $N^{\circ} 31043$ que impide a los sentenciados en primera instancia postular a cargos públicos o ejercer funciones públicas por la comisión de delito doloso, siendo que las personas que se encuentren bajo tales supuestos no podrán ser congresistas, y en consecuencia, no podrán aprovecharse de las garantías parlamentarias.

En ese sentido, la pregunta vendría a ser qué reformas se le puede hacer a la "inmunidad parlamentaria". Se tiene algunas observaciones respecto de los dos tipos de inmunidad en sentido estricto que deben tomarse en cuenta para ser regulados. Algunas ya las hemos mencionado como la existencia de vacíos legales respecto de la inmunidad de arresto, y recogemos otras que fueron hechas por David Dumet, en la disertación que brindó el 10 de octubre como parte de una sesión académica organizada por el Taller de Derecho Constitucional de la UNMSM, respecto de la celeridad del procedimiento de levantamiento de la inmunidad, y sobre la eliminación de la extensión de esta prerrogativa hasta un mes después de dejar el cargo de congresista, extensión que considera no tiene fundamentos que la justifiquen.

Sin perjuicio de ello, y para garantizar una reforma integral, podrían tomarse los criterios y lineamientos planteados por la Comisión de Venecia (2014, p. 30) en su reporte titulado "Report on the scope and lifting of parliamentary immunities":

National rules on parliamentary inviolability should:

- be subject to limitations laid down in law or parliamentary rules of procedure

- be of a temporal nature, so that proceedings can be brought at a later stage

- be possible to lift, following clear and impartial procedures

- not protect against preliminary investigations of the case concerned

- not apply if the member is caught in flagrante delicto

- not apply to particularly serious criminal offences

- not apply to minor or administrative offences.

Las normas nacionales sobre la inviolabilidad parlamentaria deberían: 
- estar sujetas a limitaciones establecidas en la ley o en las normas de procedimiento parlamentarios.

- ser de naturaleza temporal, de manera que los procesos judiciales puedan iniciarse terminado el ejercicio del cargo como parlamentario.

- ser posible de ser levantada, siguiendo procedimientos claros e imparciales.

- no alcanzar a las investigaciones preliminares de la acusación.

- no ser aplicable a los miembros del parlamento atrapados en delito flagrante.

- no ser aplicable a infracciones penales consideradas graves.

- no ser aplicable a infracciones menores ni administrativas.

(Traducción nuestra).

\section{Conclusiones}

Los argumentos a favor de la eliminación de la inmunidad parlamentaria son legítimos; sin embargo, no son suficientes para justificarla, pues responden a pasiones políticas que crean un velo sobre esta institución.

La inmunidad parlamentaria aún no ha perdido su vigencia. En un Estado social y democrático de derecho, como el nuestro, lo más idóneo es que se evalúen también los argumentos que abogan por su no supresión, y se recuerde su importancia como garantía institucional del Congreso, y como un poder propio del Poder Legislativo que contribuye al sistema de controles y equilibrios de poderes.

Debería reconsiderarse la eliminación de la inmunidad parlamentaria, y en su defecto, buscar reformarla. La existencia de vacíos en la regulación de esta figura da pie a que sea mal utilizada por los congresistas. Frente a ello, debería darse una reforma integral de esta institución en aras de regularizar su aplicación. Empero, la competencia sobre el levantamiento de la inmunidad no puede ser delegada a un órgano distinto al Congreso, pues se perdería en parte la finalidad protectora de esta prerrogativa, protección sobre el Poder Legislativo frente a la injerencia de los otros poderes.

\section{REFERENCIAS}

- Bazo, A. (7 de julio de 2020). ¿Qué hizo el congreso con el proyecto sobre inmunidad y por qué la decisión sería inconstitucional?. RPP Noticias. Recuperado de: https://rpp.pe/ politica/congreso/inmunidad-parlamentaria-que-hizo-el-congreso-con-el- proyecto-original-ypor-que-la-decision-seria-inconstitucional-noticia-1278215?ref=rpp

- Canales, P. \& Loiseau Virginie. (1999). Desafuero parlamentario en Chile. Recuperado de: http://www2.congreso.gob.pe/sicr/cendocbib/con_uibd.nsf/10E44AC15DA44914052574A60 0700979/\$FILE/desafuero_chile.pdf

- Congreso de la República(2019). Informe de Opinión Consultiva Nº2-2018-2019. Recuperado de: http://www.congreso.gob.pe/Docs/comisiones2018/ConstitucionReglamento/files/sobre_ las_causales_para_el_levantamiento_de_inmunidad_parlamentaria_de_arresto.pdf

- Congreso de la República (2020). Proyecto Ley No 4855/2020-CR. Texto sustitutorio de la Ley de Reforma constitucional que elimina la inmunidad parlamentaria y reduce otras prerrogativas. Recuperado de: https://leyes.congreso.gob.pe/Documentos/2016_2021/ Texto_Sustitutorio/Proyectos_de_Le y/TS04855-20200705-.pdf

- Congreso de la República (2020). Proyecto Ley N 4882/2020-CR. Ley de reforma Constitucional que precisa y regula la inmunidad parlamentaria. Recuperado de https:// leyes.congreso.gob.pe/Documentos/2016_2021/Proyectos_de_Ley_y_de_Resolucion es_ Legislativas/PL04882_20200324..pdf

- Congreso de la República (2020). Proyecto Ley N 4939/2020-CR. Ley que reforma el artículo 93 de la Constitución. Recuperado de: https://leyes.congreso.gob.pe/Documentos/2016_2021/ Proyectos_de_Ley_y_de_Resolucion es_Legislativas/PL04939_20200326..pdf 
- Comisión de Venecia. (2014). Report on the scope and lifting of parliamentary immunities. Recuperado de: https://www.venice.coe.int/webforms/documents/default.aspx?pdffile=CDLAD(2014)011-e

- Dumet, D. (10 de octubre de 2020). Inmunidad Parlamentaria. Derecho parlamentario. Sesión académica organizada por el Taller de Estudios de Derecho Constitucional - UNMSM. Recuperado de: https://m.facebook.com/story.php?story_fbid=3247022035424526\& id $=306489266401124$

- La Ley. (7 de julio de 2020). Presidenta del TC: Reforma constitucional que elimina la inmunidad parlamentaria afecta la autonomía de los magistrados. La Ley. Recuperado de: https://laley.pe/art/9904/presidenta-del-tc-reforma-constitucional-que-elimina-la-inmunidadafecta-la-autonomia-de-los-magistrados

- La Rosa, R (22 de noviembre de 2019). El Comercio-Ipsos: Un 78\% está a favor de eliminar la inmunidad parlamentaria. El Comercio. Recuperado de: https://elcomercio.pe/politica/ el- comercio-ipsos-un-78-esta-a-favor-de-eliminar-la-inmunidad-parlamentaria-el-comercioipsos-elecciones-2020-noticia/?ref=ecr

- Poder Ejecutivo. (2020). Proyecto Ley N4416-2018-PE. Ley de Reforma Constitucional que modifica el artículo 93 de la Constitución. Recuperado de: https://leyes.congreso. gob.pe/Documentos/2016_2021/Proyectos_de_Ley_y_de_Resolucion es_Legislativas/ PL0441620190604..pdf

- Proética. (2019). La Inmunidad Parlamentaria. Breve análisis de esta prerrogativa constitucional. Recuperado de: https://www.proetica.org.pe/wp- content/uploads/2019/06/ Inmunidad-Parlamentaria.-Breve-an\%C3\%A1lisis-de-esta- prerrogativa-constitucional.pdf

- Redacción EC. (2 de mayo de 2019). Edwin Donayre: la cronología tras su condena por el caso "gasolinazo". El Comercio Recuperado de: https://elcomercio.pe/politica/edwindonayre-cronologia-situacion-caso-gasolinazo-noticia-604197-noticia/?ref=ecr

- Redacción EC. (13 de febrero de 2019). Comisión de Constitución aprobó informe consultivo Caso Edwin Donayre. El Comercio. Recuperado de: https://elcomercio.pe/politica/comisionconstitucion-aprobo-opinion-consultiva-caso-edwin- donayre-noticia-nndc-607060-noticia/

- Redacción RPP Noticias (6 de julio de 2020). Martín Vizcarra: "Nos quieren tomar el pelo y que la eliminación de la inmunidad se caiga por inconstitucional. Rpp. Noticias. Recuperado de: https://rpp.pe/politica/gobierno/martin-vizcarra-nos-quieren-tomar-el-pelo-y-que-laeliminacion-de-inmunidad-se-caiga-por-inconstitucional-noticia-1278011

- Redacción RPP Noticias. (04 de junio de 2019). Poder Judicial solicitó levantar inmunidad parlamentaria a congresista de Fuerza Popular. Rpp Noticias. Recuperado de: https://rpp. $\mathrm{pe} /$ politica/congreso/betty-ananculi-poder-judicial-solicito-levantar-inmunidad- parlamentariaa-congresista-de-fuerza-popular-noticia-1200863? ref=rpp

- Redacción RPP Noticias. (27 de agosto de 2018). Pj condena a 5 años y 6 meses de prisión efectiva a congresista Edwin Donayre. Rpp Noticias. Recuperado de: https://rpp. pe/politica/congreso/pj-condena-a-5-anos-de-prision-efectiva-a-congresista- edwin-donayrenoticia-1146109

- Redacción RPP Noticias. (23 de abril de 2018). Congresista Fujimorista Betty Ananculi es acusada de falsificar estudios. Rpp Noticias. Recuperado de: https://rpp.pe/politica/congreso/ congresista-fujimorista-betty-ananculi-es-acusada-de- falsificar-estudios-noticia-1118228

- Redacción RPP Noticias. (10 de mayo de 2012). Archivan pedido de levantamiento de inmunidad a Congresista Raffo. Rpp Noticias. Recuperado de: https://rpp.pe/politica/actualidad/ archivan-pedido-de-levantamiento-de-inmunidad-a- congresista-raffo-noticia-264392

- Redacción RPP Noticias (3 de enero de 2012). Carlos Raffo recibió ilegalmente dinero de Montesinos, según sentencia. Rpp Noticias. Recuperado de: https://rpp.pe/politica/actualidad/ carlos-raffo-recibio-ilegalmente-dinero-de-montesinos- segun-sentencia-noticia-437250 
- Tacuche, R. (2017). Inmunidad parlamentaria y corrupción en el Perú: Teoría del caso Carlos Raffo (Tesis de grado). Universidad Cesar Vallejo, Lima, Perú. Recuperado de: http:// repositorio.ucv.edu.pe/handle/20.500.12692/15340

- Tribunal Constitucional. (01 de diciembre de 2003). EXP. N 00006-2003-PI/TC. Recuperado de: https://tc.gob.pe/jurisprudencia/2003/00006-2003-Al.pdf

- Tribunal Constitucional. (30 de octubre de 2006). EXP. N 00026-2006-PI/TC. Recuperado de: https://tc.gob.pe/jurisprudencia/2007/00026-2006-Al.pdf

- Tribunal Constitucional. (04 de enero de 2010). EXP. N 00013-2009-PI/TC. Recuperado de: https://tc.gob.pe/jurisprudencia/2010/00013-2009-Al.pdf

Fecha de recepción: 23 de octubre de 2020

Fecha de aceptación:06 de noviembre de 2020 